\title{
A FUNÇÃo DE JULGAR NO NOVO CÓDIGO DE PROCESSO CIVIL: AS INTERAÇÕES ENTRE O FORMALISMO JURÍDICO E O FORMALISMO DEMOCRÁTICO
}

\author{
THE ASSIGNMENT OF JUDGING IN THE NEW CODE OF CIVIL PROCEDURE: \\ THE INTERACTIONS BETWEEN THE LEGAL FORMALISM AND DEMOCRATIC \\ FORMALISM
}

\begin{abstract}
Alan Da Silva Esteves ${ }^{1}$
Andreas Krell $^{2}$

\section{RESUMO}

A função de julgar no novo Código de Processo Civil acontece a partir de interações entre o formalismo clássico e o formalismo democrático. As teorias da hermenêutica constitucional, da lei adjetiva civil e do positivismo tradicional são utilizadas com o objetivo de reafirmar a necessidade de fundamentação da decisão judicial no grau maior de qualidade. É necessário perceber as mudanças de padrões sobre a interpretação jurídica e o ato de julgar. A concepção de jurisdição no Estado Constitucional conecta-se aos princípios constitucionais de justiça e aos direitos fundamentais, além de aproximar os aspectos formais aos materiais.
\end{abstract}

Palavras-chave: Formalismo clássico, Formalismo democrático, Novo CPC, Ato de julgamento

\begin{abstract}
The assignment of judging in the new Code of Civil Procedure starts with the interactions between classical formalism and democratic formalism. The theories of constitutional hermeneutics, of civil adjectival law and of traditional Positivism are used in order to reaffirm the requirement of motivating the judgment in the higher degree of quality. It is necessary to understand the changes of the standards on the legal interpretation and the act of judging. The concept of jurisdiction in the Constitutional State connects to the constitutional principles of justice and fundamental rights, and approach the formal aspects of materials.
\end{abstract}

Keywords: Classical formalism, Democratic formalism, new CPC, Act of judgment

\footnotetext{
${ }^{1}$ Mestrado em Direito pela Universidade Federal de Alagoas - UFAL, Alagoas, (Brasil). Juiz do Trabalho pela $7^{\mathrm{a}}$ Vara do Trabalho de Maceió, Alagoas, (Brasil). E-mail: alan.esteves@trt19.jus.br

2 Doutorado em Direito pela Freie Universität Berlin - FU, Berlim, (Alemanha). Professor de Direito Ambiental e Constitucional da Universidade Federal de Alagoas - UFAL, Alagoas, (Brasil). E-mail: akrell@uol.com.br
} 


\section{INTRODUÇÃO}

O trabalho tem como objetivo estabelecer uma relação entre a função de julgar e as espécies de formalismo: o clássico e o democrático, este último anunciado no novo Código de Processo Civil (CPC), Lei n. 13.105, de 16 de março de 2015, e dentro do contexto da abrangência dos caracteres da jurisdição no Estado Constitucional. Estes objetivos servem para obter respostas às seguintes indagações: (a) por que a aplicação do NCPC, no que se refere à noção de sentença não fundamentada, tem que passar pelo entendimento da nova concepção de jurisdição no Estado Constitucional? (b) o que é o formalismo na sua forma clássica? (c) o que é o formalismo democrático no NCPC? (c) quais as conexões destas espécies e como se apresentam para inferir uma teoria da aproximação do direito formal ao direito material?

Com efeito, formula-se de logo a hipótese principal de que a interação do formalismo clássico com o formalismo democrático não é um dado recente, mas construído de decisões judiciais que aplicam a Constituição Federal e demais leis no vai e vem de textos válidos e vigentes com os casos concretos, que se fazem normas pela construção de significados, tornam-se decisões, entrelaçam-se de novo para, mais uma vez, voltar novamente a ser Constituição, ${ }^{3}$ especialmente quando: (1) tem-se que lidar com os conceitos jurídicos plurissignificativos; (2) muda o foco do método de interpretação, especialmente do lógicosistemático para o teleológico; (3) tem relação com o entender e aperfeiçoar a jurisdição no Estado Constitucional, não só para assegurar o primado da lei, mas também para relacionar-se com os princípios constitucionais de justiça e os direitos fundamentais.

O tema tem relevância para a ciência jurídica quando traz importantes debates para o estudo, tais como: (a) a forma de resolução de conflitos e sua interação com o formalismo existente; (b) os influxos da Constituição no NCPC, no sentido de introduzir outra forma de justificação legal pela explicar os conceitos e inferir quando uma decisão judicial não se encontra fundamentada; (c) os impactos na forma de se pensar o direito com o respeito do princípio do primado da lei e a construção das bases da teoria de aproximação do direito formal e material.

\footnotetext{
${ }^{3}$ A ideia de entrelaçamento de textos e significados que se misturam e tudo volta a ter natureza constitucional foi concebida a partir das ideias de João Maurício ADEODATO (A retórica constitucional. São Paulo: Saraiva, 2009, p. 140).
} 
A contextualização passa por perceber o funcionamento da jurisdição constitucional quando tem que lidar com os conceitos jurídicos, especialmente os indeterminados, e os contornos de dizer o direito dentro de um raciocínio que pode ser amplo ou reduzido, a depender do subjetivismo ou objetivismo do itinerário que fez o estado-juiz. As linhas de pesquisa utilizadas acontecem a partir de uma relação da teoria do positivismo jurídico, da lei adjetiva civil e, também, da jurisdição constitucional.

\section{A INSEGURANÇA JURÍDICA COMO UM DOS PRINCIPAIS PROBLEMAS DA JURISDIÇÃO BRASILEIRA}

Uma pesquisa promovida pela Secretaria de Assuntos Legislativos do Ministério da Justiça e liderada por diversos pesquisadores do direito, ${ }^{4}$ selecionou de um grande número de decisões do STF (692 ADI, 35 ADPF e 15 ADC) um total de 40 acórdãos relacionados à segurança pública, reforma do Judiciário e do processo e competição política, apontando a "artifícios instrumentalizados pelas decisões no intuito de atalhar suas fundamentações", destacando-se o uso da doutrina "como argumento de autoridade sem a contextualização de sua citação com o caso analisado", a citação de "pedaços de legislação desconectados, em concreto, com a tópica" e a recorrência à jurisprudência "também como argumento de autoridade, sem explicitação de sua correlação com o caso".5

Ficou patente que os ministros utilizam todos os tipos de argumentos para fundamentar suas decisões, não havendo um "padrão decisório", uma vez que diferentes formas argumentativas podem ser empregadas num mesmo voto. Por isso, a caracterização mais adequada seria um "mosaico de argumentos de tipos diversos", entre os quais se destacam os "que recorrem a uma interpretação sistematizada da lei e dos princípios de direito e os que lançam mão da doutrina, da jurisprudência ou da opinião de especialistas de áreas nãojurídicas". 6

A Comissão de Juristas para Elaboração do Novo CPC, na sua exposição de motivos, constatou que há no Brasil "[...] indefinidamente, posicionamentos diferentes e incompatíveis, nos Tribunais, a respeito da mesma norma jurídica", fato que "leva a que jurisdicionados que estejam em situações idênticas, tenham de submeter-se a regras de conduta diferentes, ditadas 
por decisões judiciais emanadas de tribunais diversos", sendo este um "fenômeno fragmenta o sistema, gera intranquilidade e, por vezes, verdadeira perplexidade na sociedade". 7

A validade da norma em que está baseada uma decisão jurídica não é suficiente para dar lastro a sua legitimação e sua correção. Por isso, o novo CPC institucionalizou a necessidade "de justificar como se chegou ao preenchimento do sentido das normas", fazendo com que o aplicador deve "fundamentar o caminho argumentativo que o levou a estabelecer, no processo de aplicação/ interpretação da norma, aquele determinado fim". 8

Marinoni enfatiza que "não se deve confundir direito ao processo justo com direito à decisão racional e justa". Para o autor, falta racionalidade à decisão judicial "que se distancia de decisão anterior, proferida pelo mesmo órgão jurisdicional em caso similar (...)". Isto quer dizer que a legitimação da jurisdição depende também do próprio conteúdo da decisão que deve, inclusive, estar "ajustado ao conteúdo dos direitos fundamentais". A maioria das decisões judiciais exige o uso de pontos argumentativos não obtidos por meio de uma mera subsunção dedutiva. Isto significa que a racionalidade do discurso judicial "vai além daquilo que tradicionalmente se concebe como jurídico", tornando-se um discurso prático ou moral. ${ }^{9}$

\section{A TEORIA FORMALISTA CLÁSSICA}

A teoria formalista clássica tem como ponto de partida a ideia de que os aspectos formais precedem a extração de conclusões substantivas. Na verdade, ela representa uma "teoria implícita do direito" na medida em que alega que "o direito se elabora a partir de si mesmo". 10

\footnotetext{
4 RODRIGUEZ, José Rodrigo et al. Processo legislativo e controle de constitucionalidade: as fronteiras entre o direito e a política. Brasília: MJ/CEBRAP, 2010.

5 JALES, Túlio de Medeiros. Novo Código de Processo Civil e fundamentação da decisão judicial: horizontes argumentativo e hermenêutico. Revista Direito e Liberdade, v. 17, n. 3, Natal, set./dez. 2015, p. 264 s.

${ }^{6}$ RODRIGUEZ, José Rodrigo et al. Ob. cit., p. 77.

${ }^{7}$ Disponível em: <www.osconstitucionalistas.com.br/novo-codigo-de-processo-civil〉. Acesso em: 15.1.2016.

${ }^{8}$ JALES, Túlio de M. Ob. cit., p. 274.

9 MARINONI, Luiz G. O precedente na dimensão da igualdade. 2010. Disponível em: <www.marinoni.adv.br/artigos.php>. Acesso em: 19.2.2016.
} 
Tal doutrina busca, assim, analisar as diversas conexões entre as partes a partir dos conceitos, princípios e processos, em si e conjuntamente, além do papel de como os tribunais analisam a controvérsia. Trata, pois, de inferir o direito na sua dimensão normativa; por conseguinte, há se de perceber, logo de início, que ela opera dentro de um duelo entre o formal e o substancial desde a análise de condições mínimas, passando por coerências justificatórias até os esclarecimentos, estes no sentido de se apoiar em certos objetivos ditos substanciais.

Com efeito, a concepção formal trabalha a perspectiva de como o direito se produz e não o que ele estabelece, por isso seu escopo de preferência é o agir do intérprete segundo a interpretação lógico-sistemática. ${ }^{11}$ Daí vem a importância, para o formalista, de compreender a linguagem que materializa as chamadas formas deônticas do direito: o permitido, o proibido e o obrigatório. Diz-se, então, que a norma jurídica tem um dever ser relacional em que o fenômeno linguístico sintetiza ou relaciona os conceitos que se referem aos dados da experiência. ${ }^{12}$

Esse indicativo do explicar-se pela linguagem do direito positivo acontece porque, a partir dela, tem-se a estrutura reduzida ao formal como ponte para efetivar o direito material. Melhores explicações de tais assertivas são as seguintes: para encontrar o permitido, o proibido e o obrigatório na regra jurídica dentro da dimensão normativa, o juiz ou intérprete irá fazer generalizações formais de grau a grau do domínio formal para o material. ${ }^{13}$ Trata-se de conjecturas para acertamento do fato e acontece como se dissesse várias vezes: deve ser isso, deve ser aquilo, deve ser aquilo outro, e assim sucessivamente.

Radbruch explica a respeito que "proposições de dever ser só podem ser fundamentadas e demonstradas mediante outras proposições do dever ser", sendo que "as proposições últimas do dever ser são indemonstráveis, axiomáticas, não passíveis de conhecimento, mas apenas de crença". ${ }^{14}$

10 WEINRIB, Ernest. Legal formalism on the immanent rationality of Law. In: RODRIGUEZ, J.R. (Org.). Justificação do Formalismo Jurídico. São Paulo: Saraiva, 2011, p. 270.

${ }^{11}$ BOBBIO, Norberto. O positivismo jurídico: lições de filosofia do direito. São Paulo: Ícone, 1995, p. 144ss. 12 VILANOVA, Lourival. Ob. Cit., p. 105.

${ }^{13}$ RADBRUCH, Gustav. Filosofia do Direito. São Paulo: Martins Fontes, 2004, p. 17. 
Isso se verifica num grau de importância maior nos conceitos jurídicos considerados abertos - aqueles sem as estruturas do "antecedente" e do "consequente" perfeitamente identificadas -, pois, como as circunstâncias da vida contemporânea são cada vez mais intricadas, é função do juiz fazer com que os fatos caibam dentro da hipótese da norma. ${ }^{15} \mathrm{O}$ problema é como fazer. No caso do Direito Constitucional e seus princípios plurissignificativos, trata-se de assegurar o princípio do primado da lei e de controlar a arbitrariedade do juiz ou intérprete, até porque conceitos genéricos encorajam o despotismo. ${ }^{16}$

Por isso, reafirma-se que o formalismo, na sua abordagem tradicional, representa uma ideia que vive intrincada ao direito por sempre requerer que haja justificação legal para entender conexões e interações das partes e o papel dos tribunais. Neste ponto, a fidelidade da dimensão normativa do direito ao pensamento jurídico e à tradição filosófica remonta à Antiguidade clássica. ${ }^{17} \mathrm{O}$ direito, como guia do comportamento humano, do dever ser formulado inúmeras vezes, não surge do nada, mas precisa de um roteiro relacional com os fatos para poder explicar-se e ser explicado, de interações do todo e das partes jurídicas do corpo constitucional-legislativo. Por isso, o formalismo é tão importante quanto o resultado que definiu o próprio direito em si.

\section{OS PRINCIPAIS CARACTERES DA JURISDIÇÃO NO ESTADO CONSTITUCIONAL}

Observado como se processa o pensamento formalista, que objetiva esclarecer como a decisão judicial deve se portar para explanar como chegou ao resultado, de sua preferência pela interpretação lógico-sistemática dada pela dimensão normativa do direito, cabe inferir quais os principais caracteres da jurisdição do Estado Constitucional para entender as bases do formalismo democrático que está presente no Novo Código de Processo Civil.

\footnotetext{
${ }^{14}$ PONTES DE MIRANDA, F. C. Tratado de Direito Privado - t. I. 2. ed. Campinas: Bookseller, 2000, p. 20.

15 FARIAS, Domenico. Idealità e indeterminatezza dei principi constitucionali. Milano: Giuffré, 1981, p. 9ss.

16 WEINRIB, Ernest. Ob. cit., p. 259ss.

${ }^{17}$ Cf. ADEODATO, João Maurício. A retórica constitucional. São Paulo: Saraiva, 2009, p. 139ss.
} 
No Estado Constitucional, a jurisdição funciona com inferência dos seguintes contextos: (a) admitir a complexidade no mundo contemporâneo segundo sua época, através de reanálises sociológicas; (b) separação do texto e norma jurídica - nova face da dimensão normativa do direito - dever ser tende a começar pela crença; (c) realizar ou restringir direitos tem que seguir os valores da Constituição dentro do que sejam os princípios materiais de justiça e os direitos fundamentais, ou seja, também uma leitura renovada da dimensão axiológica. $^{18}$

Sobre os textos e os conceitos jurídicos que saem do papel para novas reconfigurações e demonstrações de como o universo social anda complicado, difícil e rico de alternativas, apesar de não ser o propósito deste trabalho fazer a análise jurisprudencial de caso paradigmático, basta ver a decisão do STF na Ação Direita de Inconstitucionalidade (ADI) n. 4277, e na Arguição de Descumprimento de Preceito Fundamental (ADPF) n. 132, que decidiu reconhecer a união estável para casais do mesmo sexo a despeito do texto de lei falar especificamente em homem e mulher. Com efeito, aconteceu uma interpretação conforme a Constituição no sentido de combater as discriminações, emprestar o efeito vinculante para "afastar qualquer significado do art. 1.723 do Código Civil que impeça o reconhecimento de pessoas do mesmo sexo como entidade familiar". ${ }^{19}$

Em outros termos, o que fez aquele tribunal foi o uso de raciocínio ampliativo dos termos "homem e mulher" do referido $\operatorname{artigo~}^{20}$ e incluir neles os grupos socialmente excluídos da possibilidade de união estável, como os homossexuais, as lésbicas e os transgênicos. Tratase de um exemplo em que a dimensão sociológica do direito é revista no sentido progressivo de abrangência de excluídos.

Dada tal complexidade social, a separação de texto e norma jurídica é uma evidência ao dizer o direito no Estado Constitucional e que impacta sobremaneira na sua dimensão normativa. Assim, apesar de se reconhecer que os elementos textuais e os métodos tradicionais e específicos são importantes, a norma jurídica é formada por uma gama de concretizações que vão das regras válidas até as decisões, que depois voltam à Constituição para fazer novos pontos de partida. Daí a relevância da casuística em fazer uma operação de conectar a norma geral e a norma do caso concreto, a qual vai sendo reelaborada toda vez que houver discrepância entre o texto e a realidade. ${ }^{21}$ 
Nesse sentido, é preciso observar a existência de conexões recíprocas entre o interpretar da regra jurídica pela busca do sentido e o alcance diante do caso concreto, além do caso concreto, que vem dando sentido e alcance à regra jurídica. Assim, “a norma individual, ou a sentença, outorga características ao caso, mas é impossível ignorar que, na atualidade - diante do pluralismo da sociedade e da constante transformação dos fatos sociais -, é necessário muito mais do que isso, uma vez que a interpretação da lei, ou da norma formulada pelo juiz, depende do 'sentido' do caso concreto". ${ }^{22}$ (Grifo no original).

A partir dessas constatações houve uma busca teórica e prática para que o interpretar da regra jurídica pudesse responder aos valores do Estado Constitucional. Era um caminho até óbvio, porque se não fosse assim cada juiz ou intérprete passaria a interpretar segundo os seus próprios valores e imporia ditaduras judicantes ou interpretativas a partir de imposições morais de como os cidadãos deveriam se comportar. Por isso, a submissão da lei às normas da Lei Maior implica uma das mais importantes características do constitucionalismo contemporâneo: sua conformação aos princípios constitucionais de justiça e aos direitos fundamentais. $^{23}$

Nesse compasso, Sarlet inferiu ideia assemelhada a partir de considerações sobre o preâmbulo da Constituição ${ }^{24}$ e de sua relevante força jurídica valorativa que se materializa através da sintetização dos valores e/ou da noção de direito e de justiça, da consignação das circunstâncias, das razões que envolvem sua elaboração e das motivações que asseguram sua legitimidade, da enunciação de objetivos e promessas e da normatividade idêntica aos princípios contidos na parte permanente da Constituição. ${ }^{25}$

Assim, o preâmbulo da Carta de 1988 reflete bem o novo sentido à jurisdição.

\footnotetext{
${ }^{18}$ Cf. ADEODATO, João Maurício. A retórica constitucional. São Paulo: Saraiva, 2009, p. 139ss.

${ }^{19}$ Disponível em: <www.stf.jus.br/portal/cms/verNoticiaDetalhe.asp?idConteudo=178931>. Acesso: 1.2.2016

${ }^{20}$ Dispõe o art. 1.723 CC: "É reconhecida como entidade familiar a união estável entre o homem e a mulher, configurada na convivência pública, contínua e duradoura e estabelecida com o objetivo de constituição de família."

21 ADEODATO, João M. Ob. cit., p. 142ss.

22 MARINOni, L. G.; AREnhart, S. C.; Mitidiero, D. Novo Curso de Processo Civil. V. 1. São Paulo: RT, 2015, p. 102.

23 Ob. cit., p. 104.
} 
Aronne, por sua vez, entende a "justiça enquanto justeza de conformação axiológica do Direito, sempre que chamado a solver conflitos de interesse". Para ele, "um papel especial resulta atribuído ao Judiciário em Estado Social e Democrático do Direito, que lhe é dado alcançar toda a esfera política e social, sendo casuisticamente legislador e administrador negativo". 26

Isso explica porque o STF reconheceu a união estável homoafetiva, possibilitando algo além dos conceitos de homem e mulher tradicionalmente considerados. Na verdade, o Tribunal fez uso de raciocínio espaçoso: para incluir os valores da Constituição presentes desde o seu preâmbulo, todos juridicizados para conformação da lei ao Estado Constitucional e para fazer valer a justiça e a igualdade. Além disso, ele assegurou os direitos individuais de minorias, na base da compreensão de que há de se buscar desenvolver uma sociedade de fraternidade, pluralista e sem preconceitos.

Entretanto, o que se deseja ressaltar como aspecto importante é que no Estado Constitucional há um encalço de finalidades constitucionais e uma ênfase em interagir com a realidade social sem estar preso ou limitado por formas dadas pelo próprio texto jurídico.

Nesse sentido, pela razão de ser do Estado Constitucional, há uma consagração da interpretação teleológica.

Em resumo, diante do que fora inferido acima, o Estado Constitucional apresenta-se com características marcantes como o reconhecimento da complexidade da sociedade, a separação entre texto jurídico e norma jurídica, a importância dos casos concretos, a tendência de conformar tudo aos princípios constitucionais de justiça e aos direitos fundamentais e a preocupação com a finalidade social das normas que inferem os valores constitucionais num indicativo de sua realização de forma progressiva.

\footnotetext{
24 "Nós, representantes do povo brasileiro reunidos em Assembleia Nacional Constituinte para instituir um Estado Democrático, destinado a assegurar o exercício dos direitos sociais e individuais, a liberdade, a segurança, o bem-estar, o desenvolvimento, a igualdade e a justiça como valores supremos de uma sociedade fraterna, pluralista e sem preconceitos, fundada na harmonia social e comprometida, na ordem interna e internacional, com a solução pacífica das controvérsias, promulgamos, sob a proteção de Deus, a seguinte Constituição da República Federativa do Brasil.”.

25 SARLET, Ingo W. Estrutura, funções e conteúdo das constituições. In: SARLET, I. W.; MARINONI, L. G.; MITIDIERO, D. Curso de Direito Constitucional. São Paulo: Saraiva, 2015, p. 74ss.

26 ARONNE, Ricardo. Razão \& caos no discurso jurídico e outros ensaios de Direito Civil-Constitucional. Porto Alegre: Livraria do Advogado, 2010, p 132.
} 


\section{A CONFORMIDADE DE DIZER O DIREITO COMO JUSTIÇA OU A POSSIBILIDADE DE JUSTIÇA: CONSTRUÇÃO DO FORMALISMO DEMOCRÁTICO NO NOVO CPC}

Viu-se que o formalismo tradicional é o modo de explicar o direito sem importar com o resultado em si. Entretanto, constatou-se que a estruturação do raciocínio aplicável à jurisdição mudou no Estado Constitucional, mormente com a necessidade de harmonia com os princípios constitucionais de justiça e os direitos fundamentais. É preciso entender por que e como o formalismo recebeu esse "acoplamento democrático" e como ele foi adotado no novo CPC.

Em geral, o nível de segurança jurídica entre os teóricos e os operadores do Direito brasileiro é bastante reduzido, visto que eles têm uma relação complicada com os conceitos jurídicos vagos, indeterminados ou plurissignificativos, inclusive os princípios constitucionais. Por isso, pode-se afirmar que no contexto atual do direito brasileiro não há uma produção coerente de decisões judiciais, principalmente quando se concebe a segurança jurídica em termos de determinação, estabilidade e previsibilidade do direito. ${ }^{27}$

Ávila alega que há justificativas para essa situação, tais como a existência de uma sociedade plural e complexa e um Estado que não resolve os problemas produzindo outros com novas legislações e buscando a cooperação para solucionar as demandas. Além disso, há uma diversidade no conhecimento das diversas fontes do direito e evidências de que os termos jurídicos atuais têm conexão com complexidades, obscuridades, incertezas, instabilidades; por fim, existe uma descontinuidade do sistema jurídico, que apresenta o juiz ou jurista como um detetive com função de detectar a norma aplicável. ${ }^{28}$

De fato, se é possível encontrar julgados que se posicionam em um sentido e outros com posições diferentes sob o mesmo fundamento, há algo que está errado no sistema jurídico. É possível citar vários exemplos para este tipo de jurisprudência "ziguezague". ${ }^{29} \mathrm{Na}$ esfera tributária, sobre as formas de extinção do crédito tributário, o STF já negou a competência para o Estado-Membro para fazer as criações, ${ }^{30}$ mas, pouco depois, passou a admiti-la. ${ }^{31}$ Com referência ao depósito recursal de $30 \%$ do valor em discussão para admissão de recurso administrativo, o STF o julgou compatível com o princípio do devido processo 
legal ${ }^{32}$ em seguida, posicionou-se em sentido contrário, invocando o mesmo princípio e acrescentando outros, como o direito de petição e o dever de proporcionalidade. ${ }^{33}$

Passado a discussão sobre a segurança jurídica, é preciso discutir a função de julgar dos tribunais. Esta possui três características básicas: resolver o problema concreto como forma imediata, aplicar corretamente a regra ao fato na sua forma mediata e, por fim, fazer o que se chama "decisão-quadro", de modo que aquilo que foi sentenciado se aplique a todos os demais conflitos que tenham os mesmos indicativos. Ocorre aqui uma tendência de valorização muito grande da jurisprudência, até mais do que a lei em si, onde há uma busca de superação e prevenção do conflito, proposta de aceleramento e exigência de uma qualidade da resposta judiciária. ${ }^{34}$

Por outro lado, os juízes e tribunais e seus protagonismos assumiram posição central desde que o Estado Constitucional foi instituído pelas constituições contemporâneas. Por conseguinte, há debates sobre a sua legitimidade democrática, o limite de suas atuações, os espaços da legislação e de jurisdição a serem respeitados e as tensões entre democracia e direito. Claro que isso faz parte de um fenômeno chamado "judicialização da política" e está conectado à ênfase no papel do Judiciário como guardião das promessas constitucionais. ${ }^{35}$

\footnotetext{
${ }^{27}$ ÁVILA, Humberto. Teoria da segurança jurídica. 3. ed. São Paulo: Malheiros, 2014, p. 48.

${ }^{28}$ Ob. cit., p. 47-64.

${ }^{29}$ Ob. cit.. p. 66ss.

${ }^{30}$ ADI 1.917 MC, Trib. Pleno, Rel. Min. Marco Aurélio, DJ 19.09.2003.

${ }^{31}$ ADI 2.405 MC, Trib. Pleno, Rel. Min. Carlos A. Britto, DJ 17.2.2006.

${ }^{32}$ ADI 1.049 MC, Trib. Pleno, Rel. Min. Carlos Veloso, DJ 25.8.1995.

${ }^{33}$ ADI 1.976, Trib. Pleno, Rel. Min. Joaquim Barbosa, DJ 18.5.2007.

${ }^{34}$ MANCUSO, Rodolfo de C. A resolução dos conflitos e a função judicial no contemporâneo Estado de Direito. 2. ed. São Paulo: RT, 2014, p . 173s.

35 TRINDADE, André K. A. O protagonismo judicial sob a perspectiva da literatura. In. STRECK, L.; TRINDADE, A. (orgs.). Os modelos de juiz: ensaios de direito e literatura. São Paulo: Atlas, 2015, p. 3ss.
} 
É cediço que a própria instituição do controle de constitucionalidade implique o envolvimento do Judiciário brasileiro em ações de cunho político, uma vez que num Estado Social, modelo adotado pela Carta de 1988, o Terceiro Poder sempre "é exigido estabelecer o sentido ou a completar o significado da legislação constitucional e ordinária que já nasce com motivações distintas às de certeza jurídica, o que dá o papel de 'legislador implícito"”. 36

No entanto, constataram-se os padrões de decisão indicadores de uma jurisprudência de "vai e vem", fato que causa perplexidades e prejuízos para a sociedade, pois as condutas dos magistrados, muitas vezes, são confusas. Esta situação se deve também ao fato de o problema de julgar na base de conceitos legais indeterminados no Estado Constitucional estar ligado ao debate sobre a existência de um espaço de discricionariedade do intérprete que realiza ou restringe os direitos fundamentais. Entretanto, os termos normativos mais abertos, em si, não explicam as falhas e as atitudes arbitrárias de juízes, legisladores e administradores. 37

Todas essas considerações são assertivas para se entender o antigo e o novo CPC com relação ao significado de julgar, quando se têm, de um lado, as relações sociais e situações coletivas com submissão dos contendores ao direito positivo e a aceitação de normas racionais sem muita participação e, de outro, os princípios constitucionais que originam uma cidadania participativa e que, também, exigem que esta seja protagonista das autonomias individuais e coletivas. $^{38}$

O novo CPC, então, funda o formalismo democrático rumo a uma cidadania participativa com objetivo de se obter uma resposta adequada em termos de conformação com os princípios constitucionais de justiça e os direitos fundamentais. A formulação de dizer o direito no âmbito do Estado Constitucional impõe a redução de subjetivismos, a correção de falhas, a redução de arbítrios e segue a trajetória da busca decisão-quadro, enfim, impõe conduzir comportamentos segundo os valores e os princípios constitucionais. O seu art. $1^{\mathrm{o}}$ já nos fornece a direção, quando reza: “O processo civil será ordenado, disciplinado e interpretado conforme os valores e as normas fundamentais estabelecidos na Constituição da República Federativa do Brasil, observando-se as disposições deste Código”.

Em relação ao termo direção, Derrida alega que "o direito é essencialmente desconstruível, ou porque é fundado, isto é, construído sobre camadas textuais interpretáveis e 
transformáveis (...), ou porque seu fundamento último, por definição, não é fundado”. ${ }^{39} \mathrm{O}$ autor apresenta o direito como possibilidade de justiça; esta, por sua vez, ele não considera (des)construível, porque ele existe fora e para além do direito. Assim, o direito não se confunde com a justiça, tendo ele algo de calculável e a justiça não. "Quando se quer ser justo" é imprescindível, portanto, valorizar aspectos como a direção, a retidão, "aquilo que não pode faltar". ${ }^{40}$

Resta a pergunta: o que não pode faltar para ser justo quando se trata de julgar no Estado Constitucional? Ao aplicar as lições de Derrida, é preciso saber aonde se quer chegar ou o percurso em que se misturam os elementos construíveis e desconstruíveis do direito, sejam os textuais, os fáticos, os objetivos, ou subjetivos e os relativos a se atingir uma decisão ou interpretação - tudo que leva apenas a possibilidade de justiça.

Pontes de Miranda, que poucas vezes falou sobre justiça, apresentou dois sentidos para ela: o suprajurídico, identificado com felicidade, difícil de ocorrer ante as muitas variáveis de ordem política, emocional, econômica etc., e a realização do direito objetivo, isto é, a exatidão em aplicar a lei que incidiu ou tem que incidir. ${ }^{41}$ A referida "retidão" de Derrida é esse algo em curso que se confunde com o "realizar" do direito objetivo ou a "exatidão" do direito que deve incidir ou incidiu para Pontes. Na verdade, trata-se da necessidade de encontrar o resultado judiciário adequado ou qualificado aos conteúdos da Constituição Federal. E aqui acontece algo como a materialização da justiça ou a possibilidade dela.

O novo CPC faz questão de abraçar tais assertivas nos parágrafos do art. 489, que estabelecem as hipóteses em que uma sentença não é considerada fundamentada, fixando, assim, os "parâmetros de qualidade" 42 da decisão judicial:

\footnotetext{
${ }^{36}$ KRELL, Andreas J. Direitos sociais e controle judicial no Brasil e na Alemanha: os (des)caminhos de um direito constitucional comparado. Porto Alegre: Sérgio Fabris Editor, 2002, p. 98.

${ }^{37}$ FARIAS, Domenico. Idealità e indeterminatezza dei principi constitucionali. Milano: Giuffré, 1981, p. 9s.

${ }^{38}$ PÊPE, Albano M. B. O que significa julgar? In. STRECK, L.; TRINDADE, A. (orgs.). Os modelos de juiz: ensaios de direito e literatura. São Paulo: Atlas, 2015, p. 11.

${ }^{39}$ DERRIDA, Jacques. A força da lei. São Paulo: Martins Fontes, 2010, p. 26. Em 1989, o autor apresentou a sua teoria da desconstrução num discurso na Cardozo Law School, com o título Desconstruction and possibility of Justice.

${ }^{40}$ Ob. cit., p. 30s.

${ }^{41}$ PONTES DE MIRANDA, F. C. Tratado de Direito Privado. T. I. 2. ed. Campinas: Bookseller, 2000, p. 40.
} 
Art. $489(\ldots)$

$\S 1^{\mathrm{Q}} \quad$ Não se considera fundamentada qualquer decisão judicial, seja ela interlocutória, sentença ou acórdão, que:

I - se limitar à indicação, à reprodução ou à paráfrase de ato normativo, sem explicar sua relação com a causa ou a questão decidida;

II - empregar conceitos jurídicos indeterminados, sem explicar o motivo concreto de sua incidência no caso;

III - invocar motivos que se prestariam a justificar qualquer outra decisão;

IV - não enfrentar todos os argumentos deduzidos no processo capazes de, em tese, infirmar a conclusão adotada pelo julgador;

V - se limitar a invocar precedente ou enunciado de súmula, sem identificar seus fundamentos determinantes nem demonstrar que o caso sob julgamento se ajusta àqueles fundamentos;

VI - deixar de seguir enunciado de súmula, jurisprudência ou precedente invocado pela parte, sem demonstrar a existência de distinção no caso em julgamento ou a superação do entendimento.

$\S 2^{\mathrm{O}}$ No caso de colisão entre normas, o juiz deve justificar o objeto e os critérios gerais da ponderação efetuada, enunciando as razões que autorizam a interferência na norma afastada e as premissas fáticas que fundamentam a conclusão.

$\S 3^{0}$ A decisão judicial deve ser interpretada a partir da conjugação de todos os seus elementos e em conformidade com o princípio da boa-fé.

Todo o cuidado com a fundamentação acontece em decorrência do Estado Constitucional. Também, há necessidade de que a decisão judicial tenha uma aceitabilidade social e seja controlável. Por isso, indicativos como racionalidade, integridade e coerência aparecem aqui configurados para que se tenha fortalecimento da jurisprudência. ${ }^{43}$ Com efeito, o novo CPC não irá resolver todos os problemas, mas deve ser compreendido como unidade e sua interpretação deve ser harmonizadora com as normas fundamentais, ou seja, deve se evitar o estudo de forma isolada de seus dispositivos. ${ }^{44}$

\footnotetext{
${ }^{42}$ WAMBIER, Teresa Arruda Alvim et al. Primeiros Comentários ao Novo Código de Processo Civil. São Paulo: RT, 2015, p. 793.

${ }^{43}$ Cf. DIDIER JR, Fredie; BRAGA, Paulo Sarno; OLIVEIRA, Rafael Alexandria de. Curso de Direito Processual Civil. Vol. 2. 10 ed. Salvador: JusPodivm, 2015, p. 316ss.

${ }^{44}$ THEDORO JÚNIOR, Humberto et al. Novo CPC: fundamentos e sistematização. 2. ed. Rio de Janeiro, 2015, p. 19s.
} 
O seu guia maior é a formação de um sistema processual efetivamente democrático com base na coparticipação e cooperação dos cidadãos a partir da consolidação de que estes são possuidores de direitos fundamentais, que assumem responsabilidades e possibilidades de interlocução ativa. São vários os seus dispositivos que consolidam tal formalismo democrático, além daquele acima citado, art. 489, quais sejam, por exemplo: (a) art. 10 ampliação do debate contraditório; (b) arts. 926-927 - decisões servem de substrato para um sistema que se vale dos precedentes como técnica decisória; (d) art. 357, § $2^{\circ}$ e $3^{\circ}$ - saneador negociado e compartilhado - trata-se de fazer uma instrução melhor preparada. ${ }^{45}$

O que se tem, na verdade, é a criação de um modelo constitucional de processo num escopo de relacionar as formas processuais com os conteúdos constitucionais. Nesse sentido, o novo CPC traz duas primazias: o julgamento de mérito (art. $4^{\circ}$ ) e o abandono de premissas rituais. ${ }^{46}$ Tal percepção conduz ao entendimento de que a forma e a garantia constitucional estão conectadas, seja para cumprir os princípios constitucionais, seja para uma leitura de um formalismo compreendido a partir da Constituição Federal no sentido de: (1) produzir um diálogo genuíno; (2) formar uma chamada "comunidade de trabalho"; (3) entender que todos são responsáveis pelo pronunciamento judicial e sua efetivação; (4) cooperação e coparticipação estão ligadas ao contraditório como influência e não surpresa. ${ }^{47}$

Nesse novo panorama, o formalismo clássico é relido pelos valores constitucionais e muda o modo de atuar dos atores jurídicos em respeito e por influência dos próprios direitos fundamentais. O foco está numa interpretação que tenha por preferência buscar e aplicar as finalidades constitucionais juridicizadas. Desta forma, "a concepção dos direitos fundamentais determina o próprio significado do Poder Público, existindo uma íntima relação entre o papel atribuído a esses direitos e o modo de organizar e exercer as funções estatais". ${ }^{48}$

\footnotetext{
${ }^{45}$ Ob. cit., p. 20 ss.

${ }^{46}$ Ob. cit., p. 26 ss.

${ }^{47}$ Ob. cit., p. 70.

${ }^{48}$ LUÑO, Antonio E. Pérez. Los derechos fundamentales. Madrid: Editorial Tecnos, 1984, p. 16. Tradução livre.
} 


\section{RELEITURA DO FORMALISMO: A POSSÍVEL TEORIA DA APROXIMAÇÃO DO MATERIAL E DO FORMAL}

O formalismo como ideia e prática inteligível de saber como se chegou a um resultado fortaleceu-se e ganhou outros contornos a partir do Novo Código de Processo Civil Brasileiro pelos influxos da jurisdição constitucional e dos valores constitucionais. Isso para aportar no que seja justiça ou possibilidade desta a partir da retidão do endereço ou realização do direito objetivo ou exatidão do direito que incide ou incidiu.

O novo CPC tem uma meta, qual seja: afastar o protagonismo judicial a partir da ideia de que de ninguém pode ter a centralidade. Todos dialogam com todos e, ao mesmo tempo, com o sistema de forma integrada e complexa. Essa visualização muda o sentido de quem viu e vê o funcionamento do aparelho estatal e das partes. Na verdade, o que se trata é de uma cultura que aos poucos se instalará, uma vez que o sistema sociojurídico brasileiro é pródigo: assinala as teorias e, depois, se buscam as práticas que a legitimem. Não que isso não viesse ocorrendo antes do novo CPC, mas acontecia de forma mais tímida.

Se o formalismo clássico partiu da concepção de que é preciso estudar como o direito se estabelece nas decisões dos tribunais, não propriamente o seu resultado, o formalismo democrático do novo CPC acontece a partir de um contraditório mais efetivo, como garantia de influência, não surpresa, além de ter base na primazia do mérito, a função de julgar é a resposta que aproxima tanto quanto possível o aspecto formal ao material.

Eis a teoria de aproximação entre a abordagem jurídica formal e material formulada com as seguintes bases: (a) a decisão judicial não deve somente ser algo que definiu o direito, mas, ao mesmo tempo, a partir do diálogo das partes e do Estado, apresentar de imediato modos de efetivação do que fora estabelecido, independentemente de recurso; (b) a decisão judicial tem um forte viés sociológico, quando impõe que as pessoas cumpram as decisões judiciais e que façam práticas de comportamento que não conduzam a outros litígios; (c) a decisão judicial alicerça as estruturas internas e externas do direito para que fiquem expostas de forma clara, no sentido de conduzir comportamentos nesse ou naquele sentido pela sociedade; (d) a decisão judicial justifica a tese de que as práticas sigam as teorias, especialmente para que os valores constitucionais sejam firmados e reafirmados como o modelo de sociedade que se deseja. 
O formalismo pensado no sentido do novo CPC representa uma adequação às diretrizes constitucionais em que aborda a democracia como um dos seus valores principais e de que as decisões sejam melhores qualificadas. Por isso, todas as estruturas de raciocínio, sejam estreitas ou largas, devem ser desconstruídas e construídas, porque o direito é texto e contexto, novamente para fazer prevalecer os conteúdos de um modelo constitucional que se deseja em processo.

A teoria da aproximação do formal ao material está presente de forma melhor delineada no art. $4^{\circ}$ do novo CPC quando reza que "as partes têm o direito de obter em prazo razoável a solução integral do mérito, incluída a atividade satisfativa”. ${ }^{49}$

A assertiva principal é a de que se exclua aqui o rigor dos requisitos procedimentais ou reinterprete-se o fluir de direitos sem a rigidez das formas. Também, que se faça a relação com as garantias constitucionais. Por isso, o formalismo na forma tradicional, agora relido pelos ditames dos direitos fundamentais e princípios materiais de justiça, adjetivado de democrático, assume uma natureza específica de que as conexões entre as partes, os conceitos e os princípios, além do trabalho de operacionalização dos tribunais, assumam papel tal qual e idêntico ao próprio resultado em si. É uma mudança de padrão.

Assim, a definição de "formalismo clássico como teoria de conhecer o direito a partir de como ele se elabora a partir de si mesmo" ${ }^{, 50}$ restrutura-se para uma teoria de conhecer o direito de como ele se elabora a partir do diálogo exauriente e, ao mesmo tempo, satisfativo.

\section{CONSIDERAÇÕES FINAIS}

Em razão do que foi exposto, é preciso inferir que o formalismo clássico opera no sistema jurídico a todo o vapor, mas ele sofrerá influxos do formalismo qualificado de democrático do novo CPC. A tradução mais plausível desse choque é a nova concepção de jurisdição que se apresenta na modernidade complexa, quando separa texto e norma jurídica e quando tende a conformar as lides aos direitos fundamentais e aos princípios constitucionais de justiça. 
As preferências da dimensão normativa, de interpretação lógico-sistemática, passam a ser pela interpretação teleológica e uso de análise de dimensões sociológicas e axiológicas. Isso quando específica o contraditório como influência, não surpresa, além de inferir a primazia do mérito. Com razão, ao privilegiar o debate profícuo e fazer efetivo o princípio constitucional do contraditório como poder/garantia de implicar decisivamente a decisão judicial, o novo CPC deseja fazer com que o processo siga os ditames constitucionais e operacionalize uma resposta adequada.

No mesmo sentido, o enfoque normativo do direito, fundamento da doutrina formalista, que se assenta no estudo das relações causais a partir dos modais deônticos do 'proibido', do 'obrigatório' e do 'permitido', vai encontrar uma nova reconfiguração do encontro do 'dever ser' a partir de conteúdos constitucionais que se relacionam aos fatos e valores nesta sociedade altamente intricada de problemas até algo definido como crença. Entretanto, o enfoque sociológico e axiológico faz o caminho de tendências com a desconstrução e construção das camadas textuais do direito para cumprimento de valores e princípios definidos na Constituição.

Daí que aquele vagar do olhar dos litígios, que era da norma para os fatos (e viceversa), feito pelo Estado-juiz, acontecerá de modo amplificado das partes e Estado-juiz para a norma, para os fatos, para a Constituição, para normas internacionais, especialmente os direitos fundamentais e os princípios constitucionais de justiça, inclusive fazendo o caminho inverso. Eis o itinerário do endereço e a exatidão do direito que incide ou deverá incidir para ser ter a possibilidade de justiça ou a justiça em si.

Ora, se a decisão judicial implica a necessidade de justificação legal para dirimir o conflito, o formalismo - como prática científica de como se chegou ao resultado - há sempre de existir. Neste contexto, o novo CPC reforça ao qualificá-lo de democrático, acentuando tendências evolutivas para confirmar um processo civil de resultados e, para tanto, exige um amplo diálogo das partes com o juiz e vice-versa.

\footnotetext{
${ }^{49}$ INTERNET. WWW.PLANALTO.COM.BR. Disponível em: <http://www.planalto.gov.br/ccivil_03/_ato2015-2018/2015/lei/113105.htm>. Acesso em 03 fev.16.18:54 horas.

50 WEINRIB, Ernest. Legal formalism on the immanent rationality of law. In: RODRIGUEZ, J. R. (org.). Justificação do formalismo jurídico. São Paulo: Saraiva, 2011, p. 270ss.
} 
Além disso, ele reconfigura na prática o papel do Estado-juiz e deseja aproximar as perspectivas do direito formal ao substancial. Para isso acontecer, impõe exigências de que tudo seja e deva ser submetido a uma instrução exauriente e definitiva a partir da dialética constante para a primazia do mérito. Por conseguinte, a resposta judicial deve ser consequência do que fora debatido e apresentar-se sem surpresas.

Enfim, o novo CPC apresenta o processo com característica de produzir resultados e consagra algo que já vinha acontecendo na prática, embora de forma ainda acanhada: a aproximação do formal ao material tanto quanto possível. Para este fim, a Constituição adapta a lei e todos os conteúdos sociais e jurídicos, conectando toda ação dentro do processo a uma garantia constitucional.

\section{REFERÊNCIAS}

ADEODATO, João Maurício. A retórica constitucional: sobre tolerância, direitos humanos e outros fundamentos éticos do direito positivo. São Paulo: Saraiva, 2009.

ARONNE, Ricardo. Razão \& caos no discurso jurídico e outros ensaios de Direito CivilConstitucional. Porto Alegre: Livraria do Advogado, 2010.

ÁVILA, Humberto. Teoria da segurança jurídica. 3. ed. São Paulo: Malheiros, 2014. BOBBIO, Norberto. O positivismo jurídico: lições de filosofia do direito. Trad.: M. Pugliesi, E. Bini e C. E. Rodrigues. São Paulo: Ícone, 1995.

DERRIDA, Jacques. A força da lei: o pensamento místico da autoridade. Trad.: L. PerroneMoíses. São Paulo: Martins Fontes, 2010.

DIDIER JÚNIOR, Fredie; BRAGA, Paulo Sarno; OLIVEIRA, Rafael Alexandria de. Curso de Direito Processual Civil - vol. 2.10. ed. Salvador: JusPodivm, 2015.

FARIAS, Domenico. Idealità e indeterminatezza dei principi constitucionali. Milano: Dott. A. Giuffré Editore, 1981. 
JALES, Túlio de Medeiros. Novo Código de Processo Civil e fundamentação da decisão judicial: horizontes argumentativo e hermenêutico. Revista Direito e Liberdade, v. 17, n. 3, Natal, p. 261-301, set./dez. 2015.

KRELL, Andreas J. Direitos Sociais e controle judicial no Brasil e na Alemanha: os (des)caminhos de um direito constitucional comparado. Porto Alegre: Sergio Fabris, 2002. LUÑO, Antonio E. Pérez. Los derechos fundamentales. Madrid: Tecnos, 1984.

MANCUSO, Rodolfo de Camargo. A resolução dos conflitos e a função judicial no contemporâneo Estado de Direito. 2. ed. São Paulo: RT, 2014.

MARINONI, Luiz Guilherme; ARENHART, Sérgio Cruz; MITIDIERO, Daniel. Curso de Processo Civil. V. 1. São Paulo: RT, 2015.

MARINONI, Luiz Guilherme. O precedente na dimensão da igualdade. 2010. Disponível em: <www.marinoni.adv.br/artigos.php>. Acesso em: 19.2.2016.

PEPÊ, Albano Marcos Bastos. O que significa julgar. In: STRECK, Lenio; TRINDADE, André K. A. (orgs.). Os modelos de juiz: ensaios de direito e literatura. São Paulo: Atlas, 2015, pp. 9-17.

PONTES DE MIRANDA, Francisco Cavalcanti. Tratado de Direito Privado. Tomo I. Atual. por Vilson Rodrigues Alves. 2. ed. Campinas: Bookseller, 2000.

PONTES DE MIRANDA, Francisco Cavalcanti. Comentários à Constituição de 1967, com a Emenda n. 1 de 1969. São Paulo: Revista dos Tribunais, 1973.

RADBRUCH, Gustav. Filosofia do Direito. Trad.: Marlene Holzhausen. São Paulo: Martins Fontes, 2004.

RODRIGUEZ, José Rodrigo et al. Processo legislativo e controle de constitucionalidade: as fronteiras entre o direito e a política. Brasília: MJ/CEBRAP, 2010.

SARLET, Ingo Wolfgang. Estrutura, funções e conteúdo das constituições. In: SARLET, I.; MARINONI, L. G.; MITIDIERO, D. Curso de Direito Constitucional. São Paulo: Saraiva, 2015. 
THEODORO JÚNIOR, Humberto et al. Novo CPC: fundamentos e sistematização. 2. ed. Rio de Janeiro: Forense, 2015.

TRINDADE, André K. A. O protagonismo judicial sob a perspectiva da literatura. In: STRECK, L.; TRINDADE, A. K. A. (orgs.). Os modelos de juiz: ensaios de direito e literatura. São Paulo: Atlas, 2015, p. 3-5.

VILANOVA, Lourival. Lógica jurídica. São Paulo: Bushatsky, 1976.

WAMBIER, Teresa Arruda Alvim et al. Primeiros comentários ao Novo Código de Processo Civil: artigo por artigo. São Paulo: RT, 2015.

WEINRIB, Ernest. Legal formalism: on the immanent rationality of law. In: RODRIGUEZ, José Rodrigo (org.). Justificação do formalismo jurídico: textos em debate. Trad. Catarina H. C. Barbieri. São Paulo: Saraiva, 2011, p. 259-270. 